\title{
Reaction mechanism of methanol dehydrogenation on a sodium carbonate catalyst
}

\author{
Shoujin Su, Michael R. Prairie ${ }^{1}$ and Albert Renken \\ Institute of Chemical Engineering, Swiss Federal Institute of Technology, Lausanne \\ (Switzerland)
}

(Received 24 June 1992, revised manuscript received 5 September 1992)

\begin{abstract}
The aim of this study is to identify the reaction mechanism of methanol dehydrogenation on sodium carbonate catalyst. Quantitative analyses of the products of methanol dehydrogenation on sodium carbonate catalyst at $963 \mathrm{~K}$ indicate that methane is formed in parallel with formaldehyde, while carbon monoxide is mainly produced from further decomposition of formaldehyde. In a specially designed fixedbed reactor, more than half of the methanol conversion takes place in the post-catalytic space, where the selectivity for formaldehyde is in the same range as for the reaction in the catalyst bed. It is therefore suggested that free radicals produced on the catalyst surface play an important role in methanol dehydrogenation. Temperature-programmed desorption of methanol on sodium carbonate and transient isotope experiments show that a hydrogen species is strongly adsorbed on the catalyst, but carbon-containing species are weakly adsorbed. Temperature-programmed reaction experiments indicate that noncatalytic thermal decomposition of formaldehyde is more significant than the surface reaction at high temperatures. Based on these facts, it is proposed that chemisorbed methanol is dissociated on the catalyst surface into adsorbed hydrogen and a gas-phase $\cdot \mathrm{CH}_{2} \mathrm{OH}$ radical. Recombination and desorption of the former is rate-determining, and the latter initiates a series of homogeneous reactions that result in the final reaction products. The proposed mechanism is useful for further improving the catalyst.
\end{abstract}

Keywords: adsorption, dehydrogenation, formaldehyde, methanol, post-catalytic reaction, sodium carbonate.

\section{INTRODUCTION}

Formaldehyde is commercially obtained by the oxidation of methanol in the presence of iron-molybdenum oxides or a silver catalyst [1]. Production of water-free formaldehyde through these procedures is expensive because they also produce water which is difficult to separate from the formaldehyde due to the formation of azeotropes [2]. The partial dehydrogenation of methanol pre-

Correspondence to: Dr. A. Renken, Institute of Chemical Engineering, Swiss Federal Institute of Technology, CH-1015 Lausanne, Switzerland. Tel. (+41-21)6933181, fax. (+41 21)6933680.

${ }^{1}$ Present address: Sandia National Laboratories, Albuquerque, NM, USA.

0926-3373/92/\$05.00 c 1992 Elsevier Science Publishers B.V. All rights reserved. 
sents an alternative to current commercial methods for producing water-free formaldehyde since water formation is avoided.

In recent work by several authors [3-7], many materials were found to exhibit catalytic activity for the dehydrogenation of methanol. Among them, sodium carbonate was shown to exhibit high activity, high selectivity for formaldehyde, and good stability at around $970 \mathrm{~K}[3,6,7]$. However, with this catalyst, carbon monoxide, methane, and trace amounts of carbon dioxide, water and coke are also produced as side products. Therefore, it is useful to identify the reaction mechanisms to provide guidance for limiting side reactions and increasing the activity of the catalyst.

The work described here indicates that methane is produced in parallel with formaldehyde, and that carbon monoxide is mainly produced through formaldehyde decomposition. Desorption experiments and transient isotopic experiments show that a hydrogen species is strongly adsorbed on the surface, but carbon-containing species desorb easily. In addition, catalyst-initiated homogeneous reactions are identified as the dominant pathway for methanol dehydrogenation in the presence of sodium carbonate catalyst. Free radicals, probably produced on the catalyst surface, initiate gas-phase chain reactions. A detailed reaction mechanism is proposed based on these facts.

\section{EXPERIMENTAL}

\section{Catalyst preparation}

The sodium carbonate catalyst was prepared by heating sodium bicarbonate (99.5\% pure, Art. 71628, Fluka, Switzerland) in air at $523 \mathrm{~K}$ for $90 \mathrm{~min}$. Then it was screened to $40-80 \mu \mathrm{m}$ diameter.

\section{Variations of selectivities with methanol conversion on the catalyst}

Attempts were made to determine how selectivities for the three main products $\left(\mathrm{CH}_{2} \mathrm{O}, \mathrm{CO}\right.$ and $\left.\mathrm{CH}_{4}\right)$ vary with conversion of methanol dehydrogenation at $963 \mathrm{~K}$. The reaction was conducted at atmospheric pressure in a flow reactor (quartz tube, internal diameter I.D. $=10 \mathrm{~mm}$ ) heated electrically. Variations in conversion were achieved by altering the catalyst mass, at a constant flowrate. The sodium carbonate catalyst was held in place with two layers of quartz wool. Temperature variations across the catalyst were less than $5 \mathrm{~K}$. Methanol vapor (mole fraction $y_{m}=0.047$ ) was fed by bubbling argon $(99.995 \%$ pure, flow-rate $196 \mathrm{ml} / \mathrm{min}$ at standard temperature and pressure (STP), i.e., 273 $\mathrm{K}, 101 \mathrm{kPa}$ ) through methanol liquid in a thermostated column. The reactor effluent was analysed with a gas chromatograph (GC) (5840A, Hewlett-Packard, USA) equipped with a thermal conductivity detector. Good separation of non-condensable components methane and carbon monoxide and analyses of 
methanol and formaldehyde were achieved simultaneously with special columns (No. 8011/2, Alltech, USA), the GC being temperature programmed. All the tubing was heated with heating bands to $390 \mathrm{~K}$ or greater to prevent formaldehyde polymerisation.

\section{Post-catalytic homogeneous reactions}

In the study of post-catalytic homogeneous reactions of methanol, $\mathrm{Na}_{2} \mathrm{CO}_{3}$ catalyst deposited on carbon fibres was used in a quartz tube reactor, as shown in Fig. 1. Support (e.g. quartz wool) below the catalyst bed was not used, because it may interfere with the homogeneous reactions. Carbon fibers were impregnated with $3.5 \mathrm{M}$ sodium carbonate solution and dried. Before and after drying, the reactor walls at both ends of the bed were washed with diluted nitric acid and water. Effluent from the reaction zone exits through a quartz capillary (I.D. $=0.5 \mathrm{~mm}$ ) sealed to the quartz tube with a silicone O-ring between the quartz tube and the capillary at the bottom. A quartz plate fixed at the top of the capillary prevents mass exchange between the reaction zone and the inert zone. The length of the reaction zone, $L$, was varied by simply displacing the capillary. The reaction was conducted at $963 \mathrm{~K}$ with the system described above, argon flow-rate being $60 \mathrm{ml} / \mathrm{min}$ (STP). The catalyst was treated with methanol under reaction conditions for $20 \mathrm{~h}$ prior to measurement to obtain a stable activity.

Transient isotope experiments of catalytic methanol dehydrogenation

Transient isotope experiments were performed using deuterated methanol $\mathrm{C}^{2} \mathrm{H}_{3} \mathrm{O}^{2} \mathrm{H}$ and methanol $\mathrm{CH}_{3} \mathrm{OH}$. The catalyst $\mathrm{Na}_{2} \mathrm{CO}_{3}$ was loaded in a quartz tube reactor $(\mathrm{I} . \mathrm{D} .=10 \mathrm{~mm}$ ) and was pretreated at $953 \mathrm{~K}$ under reaction con-

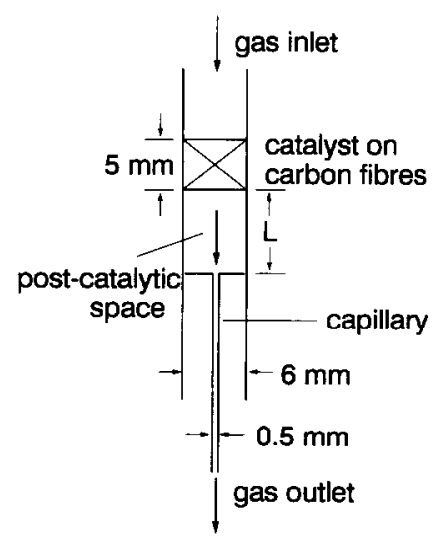

Fig. 1. The reactor used to study the post-catalytic reactions. 
ditions ( $y_{\mathrm{m}}=0.09$, carrier gas argon) for $24 \mathrm{~h}$ to obtain a stable catalyst. The measurement started when the reactor at $953 \mathrm{~K}$ was switched from $\mathrm{CH}_{3} \mathrm{OH}$ to argon for $20 \mathrm{~min}$ to purge the reactant. Next, the feed was switched to $\mathrm{C}^{2} \mathrm{H}_{3} \mathrm{O}^{2} \mathrm{H}$ $\left(y_{\mathrm{m}}=0.09\right)$. Several species including trideuterated methanol $\left(\mathrm{C}^{2} \mathrm{H}_{3} \mathrm{OH}\right.$ or $\mathrm{CH}^{2} \mathrm{H}_{2} \mathrm{O}^{2} \mathrm{H}$, mass 35 ), ${ }^{2} \mathrm{H}_{2}$ (mass 4 ) and $\mathrm{H}^{2} \mathrm{H}$ (mass 3 ), were continuously followed using a mass spectrometer (MS) (QMG420, Balzers, Lichtenstein).

\section{Temperature-programmed desorption of methanal on sodium carbonate}

Temperature-programmed desorption (TPD) of methanol on sodium carbonate was conducted in a quartz tube (I.D. $=6 \mathrm{~mm}$ ) heated electrically. A thermocouple coated with a quartz capillary was directly located in the center of the catalyst bed. Initially, the sample $(0.240 \mathrm{~g})$ was treated with methanol $\left(y_{\mathrm{m}}=0.085\right.$, carrier gas helium, flow-rate $\left.30 \mathrm{ml} / \mathrm{min}(\mathrm{STP})\right)$ at $623 \mathrm{~K}$ for 60 min to enhance chemisorption, and cooled to $298 \mathrm{~K}$ in flowing methanol. It was then purged with helium for $40 \mathrm{~min}$. The desorption was conducted by heating the sample from 298 to $993 \mathrm{~K}$ at a rate of $15 \mathrm{~K} / \mathrm{min}$. The important species, $\mathrm{H}_{2}, \mathrm{CO}, \mathrm{CH}_{2} \mathrm{O}, \mathrm{CH}_{3} \mathrm{OH}, \mathrm{H}_{2} \mathrm{O}$ and $\mathrm{CH}_{4}$, were followed continuously by MS. The procedure was then repeated for the same sample.

\section{Role of the catalyst in formaldehyde decomposition}

To study the effects of sodium carbonate on formaldehyde decomposition, temperature-programmed reaction (TPR) of formaldehyde was conducted. Continuous formaldehyde feed (mole fraction $y_{\mathrm{f}}=0.024$ ) was achieved by passing nitrogen ( $99.995 \%$ pure, $23 \mathrm{ml} / \mathrm{min}$ (STP)) through a thermostated column containing paraformaldehyde powder [7]. A quartz reactor (I.D. $=6$ $\mathrm{mm}$ ) was empty or filled with $0.200 \mathrm{~g}$ catalyst, and was heated electrically from 523 to $963 \mathrm{~K}$ at a rate of $5 \mathrm{~K} / \mathrm{min}$. Space time $(\tau)$ in the heated zone was $2.7 \mathrm{~s}$ (at $963 \mathrm{~K}$ ). The reaction effluent was analysed with the GC. Sampling was performed 10 min after the desired temperature was achieved.

\section{RESULTS}

\section{Variations of selectivities with methanol conversion on the catalyst}

Variations of formaldehyde, carbon monoxide and methane selectivities with methanol conversion are given in Fig. 2. The catalyst was on-stream for $11 \mathrm{~h}$ to achieve steady-state before the measurements were performed. In the figure, formaldehyde selectivity decreases slightly with conversion, while carbon monoxide selectivity varies contrarily and is very low at low conversions. It is probable that carbon monoxide is produced mainly from formaldehyde decom- 


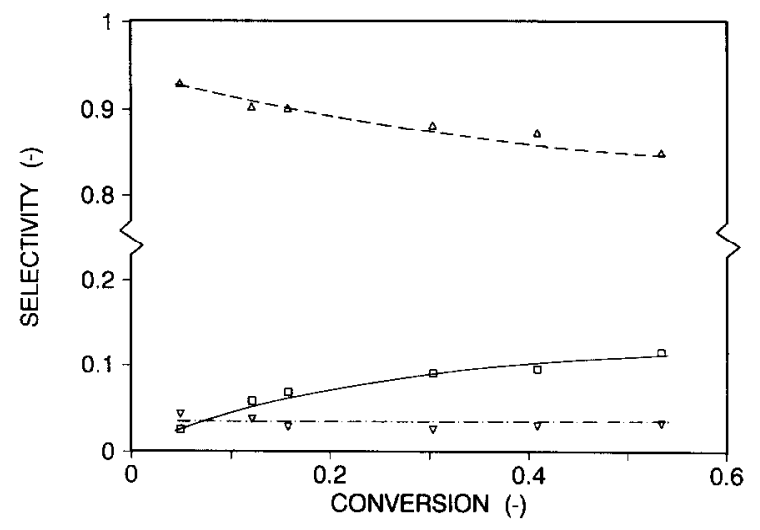

Fig. 2. Selectivities vs. conversion of $\mathrm{CH}_{3} \mathrm{OH}$ dehydrogenation. Conditions: $963 \mathrm{~K}, y_{\mathrm{m}}=0.047$, carrier gas argon $(196 \mathrm{ml} / \mathrm{min})$, catalyst mass $0.025-0.800 \mathrm{~g}$. Selectivities $(\Delta) \mathrm{CH}_{2} \mathrm{O}$; $(\square) \mathrm{CO}$; $(\nabla) \mathrm{CH}_{4}$.

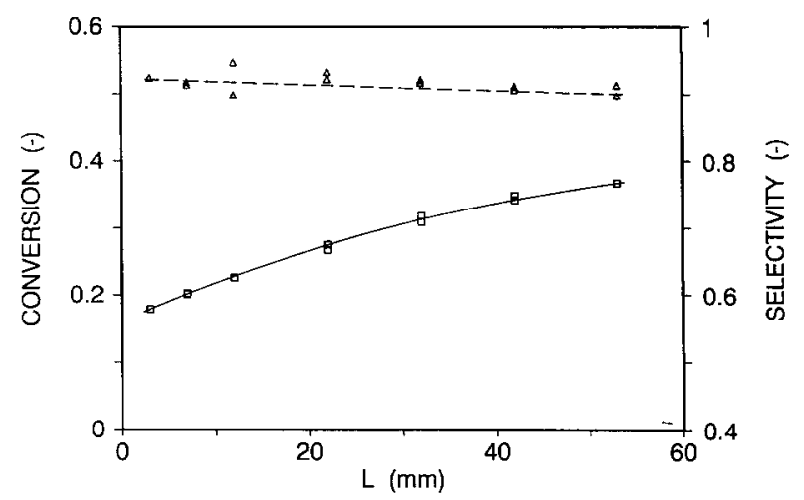

Fig. 3. Conversion and selectivity vs. length of post-catalytic zone. Conditions: $963 \mathrm{~K}, y_{\mathrm{m}}=0.047$, carrier gas argon $(60 \mathrm{ml} / \mathrm{min}), \tau=0.4 \mathrm{~s}$ at $L=50 \mathrm{~mm}$. ( $\square$ ) Conversion; $(\triangle) \mathrm{CH}_{2} \mathrm{O}$ selectivity.

position, which will be discussed later. Methane selectivity remains constant (about 0.04 ) in the range of conversion obtained. Evidently, methane is formed in parallel with formaldehyde and carbon monoxide.

Reactions in the post-catalytic space

Post-catalytic reactions were studied at $963 \mathrm{~K}$ by varying the post-catalytic volume of the reactor. The results are presented in Fig. 3. $L=0$ refers to the downstream edge of the catalyst bed.

From the figure, the reaction progresses significantly in the catalyst bed (conversion $X=0.15$ when extrapolated to $L=0$ ), whose porosity is about $80 \%$. However, more than half of the total conversion takes place after the bed $(\Delta X=0.20)$. The selectivity for formaldehyde diminishes very slightly with $L$ 
(related to methanol conversion) and is practically the same as that obtained in a normal fixed-bed reactor, which is shown in Fig. 2. This suggests that the mechanism for formaldehyde production in the post-catalytic space is the same as that in the catalyst bed, and that formaldehyde is mostly produced in the gas phase (the space between the catalytic fibers in the bed and the post-catalytic space).

To test for possible free-radical chain reactions, quartz wool was introduced into the post-catalytic volume (without the capillary). This diminishes the conversion from 0.37 to 0.20 . Comparing this with the result in Fig. 3 , it is concluded that the quartz wool caused most of the post-catalytic reaction to cease (conversion was 0.18 at $L=3 \mathrm{~mm}$ ).

To examine the catalytic activity of the reactor itself after the catalyst bed, the catalyst was carefully replaced by the same quantity of carbon fibers. In this case, methanol conversion was less than 0.01 . Therefore, the reactor wall shows no activity for methanol dehydrogenation. In addition, the non-catalytic thermal reaction is minor in the system.

It appears that certain active gas-phase species produced by reactions on the catalyst surface initiate the homogeneous reactions. Formaldehyde cannot be the active species since it did not accelerate methanol decomposition when its mixture with methanol was heated [7], although it is believed to decompose through free-radical chain reactions at high temperatures $[7,8]$. From the inhibitory effects of quartz wool, these species may be free radicals. The quartz wool may destroy the radicals, since it is commonly accepted that gas-phase free radicals are sensitive to packings.

\section{Results of the transient isotope experiment}

After the dehydrogenation of methanol $\mathrm{CH}_{3} \mathrm{OH}$ on the catalyst was interrupted and the reactor was purged of reaction gas for $20 \mathrm{~min}$, the feed was changed to $\mathrm{C}^{2} \mathrm{H}_{3} \mathrm{O}^{2} \mathrm{H}$. Then, the evolution of several species was followed using the MS, as shown in Fig. 4.

A large peak of $\mathrm{H}^{2} \mathrm{H}$ is seen, which decreases rapidly. This shows that hydrogen is stored on the catalyst and that it desorbs very slowly. It is still present after a 20 -min purge. The observation of a significant amount of trideuterated methanol indicates that the cleavage of the $\mathrm{H}-\mathrm{C}$ (or $\mathrm{H}-\mathrm{O}$ ) bond is reversible. On the other hand, no mono-deuterated methanol was observed. This shows that carbon-containing species $\cdot \mathrm{CH}_{2} \mathrm{OH}$ (or $\mathrm{CH}_{3} \mathrm{O} \cdot$ ) desorb rapidly and did not exist on the surface when $\mathrm{C}^{2} \mathrm{H}_{3} \mathrm{O}^{2} \mathrm{H}$ was introduced after the 20 min argon purge.

As seen from the declining ${ }^{2} \mathrm{H}_{2}$ concentration, the activity of the catalyst was temporarily increased after the reactor was purged of the reactant. A similar result was obtained in an experiment monitored with the GC in which 


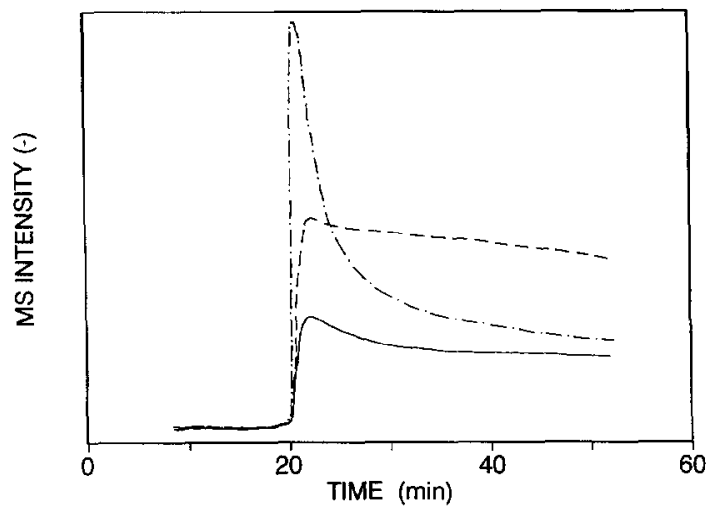

Fig. 4. Continuous mass spectrometer traces of reactor effluent. The reactor was initially stable in $\mathrm{CH}_{3} \mathrm{OH}\left(y_{\mathrm{m}}=0.09\right)$ and then switched to argon at $t=0$. At $t=20 \mathrm{~min}$, the feed was changed to $9 \% \mathrm{C}^{2} \mathrm{H}_{3} \mathrm{O}^{2} \mathrm{H}$. Experiments were performed at $953 \mathrm{~K}$, with $200 \mathrm{mg}$ of $\mathrm{Na}_{2} \mathrm{CO}_{3}$ at a total feed-rate of $50 \mathrm{ml} / \mathrm{min}$. Species: (-•-) $\mathrm{H}^{2} \mathrm{H}$; (--- ${ }^{2} \mathrm{H}_{2} ;(-) \mathrm{CH}^{2} \mathrm{H}_{2} \mathrm{O}^{2} \mathrm{H}$ and $/$ or $\mathrm{C}^{2} \mathrm{H}_{3} \mathrm{OH}$.

methanol conversion was almost doubled as a result of an argon purge for 13 min, while formaldehyde selectivity remained unchanged [7].

Adsorbed species on sodium carbonate after methanol treatment

In the TPD of methanol on the catalyst, no methane was detected and only traces of $\mathrm{CH}_{2} \mathrm{O}, \mathrm{CO}$ and $\mathrm{H}_{2} \mathrm{O}$ were seen (not shown). However, methanol and hydrogen was observed, as shown in Fig. 5 for the catalyst used once in the TPD measurement. Desorption species on the fresh sample were similar (not shown) except that several strongly adsorbed species were detected [7], which are obviously unimportant for the stable activity of the catalyst.

Methanol desorbs continuously from 300 to $800 \mathrm{~K}$, with several small peaks at $300-400 \mathrm{~K}$. This is similar to methanol adsorption on magnesium oxide [9].

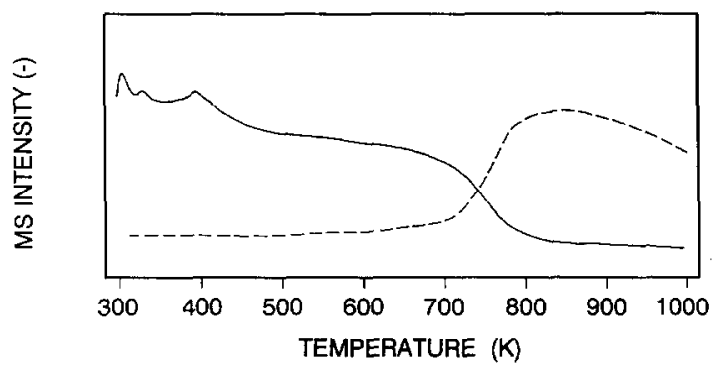

Fig. 5. Temperature-programmed desorption of $\mathrm{CH}_{3} \mathrm{OH}$ on $\mathrm{Na}_{2} \mathrm{CO}_{3}$. Sample $(0.240 \mathrm{~g})$ used once in the TPD cycle. $\mathrm{CH}_{3} \mathrm{OH}$ treatment: $623 \mathrm{~K}, 60 \mathrm{~min}$. Purging by helium: $298 \mathrm{~K}, 40 \mathrm{~min}$. Heating rate: $15 \mathrm{~K} / \mathrm{min}$. Carrier gas: helium $(30 \mathrm{ml} / \mathrm{min})$. Species: $(--) \mathrm{H}_{2} ;(-) \mathrm{CH}_{3} \mathrm{OH}$. 


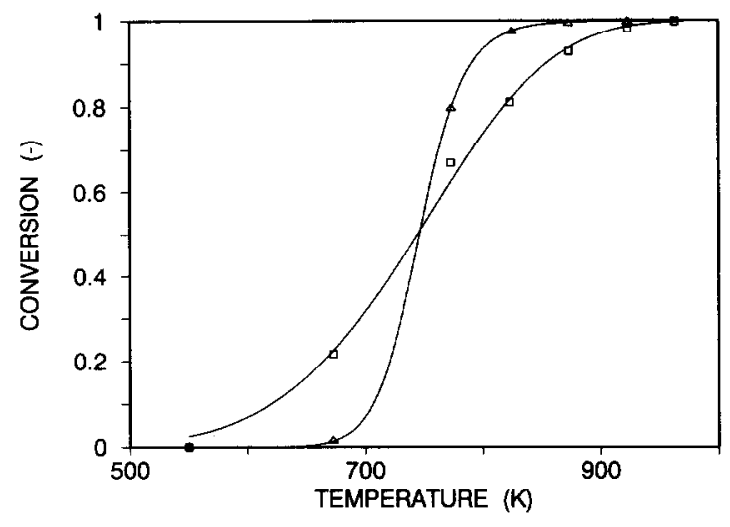

Fig. 6. Effects of $\mathrm{Na}_{2} \mathrm{CO}_{3}$ catalyst on $\mathrm{CH}_{2} \mathrm{O}$ decomposition. Conditions: $y_{f}=0.024$, carrier gas nitrogen $(23 \mathrm{ml} / \mathrm{min}), \tau=2.7 \mathrm{~s}$ (at $963 \mathrm{~K})$. ( $\square)$ With catalyst $(0.2 \mathrm{~g}) ;(\Delta)$ without catalyst.

Methanol desorbing above $350 \mathrm{~K}$ is presumably chemisorbed and is responsible for methanol activation during catalytic dehydrogenation. It may be partially non-dissociative chemisorption and partially in the form of pairs of $\cdot \mathrm{CH}_{2} \mathrm{OH}$ (and $\mathrm{CH}_{3} \mathrm{O} \cdot$ ) and hydrogen on adjacent sites as suggested by Tench et al. [9]. Significant hydrogen desorption takes place above $700 \mathrm{~K}$. Since little carbon monoxide and formaldehyde was detected, excess hydrogen exists on the surface. This hydrogen can be assumed to be left over from the reaction of methanol with the surface during the treatment at $623 \mathrm{~K}$, which produced hydrogen and easily desorbed carbon-containing species. This is in agreement with the transient isotope experiment described above.

Effects of the catalyst on formaldehyde decomposition

Formaldehyde decomposes without a catalyst at high temperatures [7]. The effects of a sodium carbonate catalyst on formaldehyde decomposition are demonstrated by a comparison between an empty reactor and a reactor filled with the catalyst. In Fig. 6 , the reaction without the catalyst is more significant above $750 \mathrm{~K}$, though the conversion is higher in the presence of the catalyst at low temperatures. The catalyst probably decreases the activation energy, nevertheless, the preexponential factor is also decreased (compensation).

\section{DISCUSSION}

From the experiments described above, atomic hydrogen is strongly adsorbed on the surface during catalytic methanol dehydrogenation. It recombines and desorbs slowly (as hydrogen), whereas the complementary $\mathrm{CH}_{3} \mathrm{O}$. or $-\mathrm{CH}_{2} \mathrm{OH}$ species desorb rapidly, if they are adsorbed at all. In addition, it is probable that free radicals from surface reactions initiate gas-phase chain re- 
actions which produce formaldehyde and other products. Therefore, we propose that the initial step in methanol dehydrogenation on sodium carbonate is a $\mathrm{H}-\mathrm{CH}_{2} \mathrm{OH}$ bond dissociation which produces surface hydrogen and a gasphase $\cdot \mathrm{CH}_{2} \mathrm{OH}$ radical. The latter undergoes a series of chain reactions. This is represented by the following equations:

On the surface:

$\mathrm{CH}_{3} \mathrm{OH}_{\mathrm{g}} \rightleftharpoons \mathrm{CH}_{3} \mathrm{OH}_{\mathrm{B}}$

$\mathrm{CH}_{3} \mathrm{OH}_{\mathrm{s}} \rightleftharpoons \cdot \mathrm{CH}_{2} \mathrm{OH}_{\mathrm{g}}+\cdot \mathrm{H}_{\mathrm{s}}$

$\mathrm{CH}_{3} \mathrm{OH}_{8} \rightleftharpoons \cdot \mathrm{OCH}_{3 \mathrm{~s}}+\cdot \mathrm{H}_{8}$

$\cdot \mathrm{OCH}_{3 \mathrm{~s}} \rightarrow \mathrm{CO}_{\mathrm{g}}+\mathrm{H}_{2 \mathrm{~g}}+\cdot \mathrm{H}_{\mathrm{s}}$

$\cdot \mathrm{OCH}_{3 \mathrm{~s}} \rightarrow \mathrm{CH}_{2} \mathrm{O}_{\mathrm{g}}+\cdot \mathrm{H}_{\mathrm{s}}$

$\cdot \mathrm{H}_{\mathrm{s}}+\mathrm{CH}_{3} \mathrm{OH}_{\mathrm{B}} \rightarrow \mathrm{H}_{2 \mathrm{~g}}+\cdot \mathrm{CH}_{2} \mathrm{OH}_{\mathrm{g}}$

$\cdot \mathrm{H}_{\mathrm{B}}+\cdot \mathrm{H}_{\mathrm{s}} \rightarrow \mathrm{H}_{2 \mathrm{~g}}$

In the gas phase:

$$
\begin{aligned}
& \mathrm{CH}_{2} \mathrm{O}_{\mathrm{g}}+\mathrm{CH}_{2} \mathrm{O}_{\mathrm{g}} \cdot \cdot \mathrm{CHO}_{\mathrm{g}}+\cdot \mathrm{CH}_{2} \mathrm{OH}_{\mathrm{g}}[8] \\
& \mathrm{CH}_{3} \mathrm{OH}_{\mathrm{g}}+\mathrm{M}^{*} \rightarrow \cdot \mathrm{CH}_{3 \mathrm{~g}}+\cdot \mathrm{OH}_{\mathrm{g}}+\mathrm{M}[10] \\
& \cdot \mathrm{CH}_{2} \mathrm{OH}_{\mathrm{g}}+\mathrm{M} \rightarrow \cdot \mathrm{H}_{\mathrm{g}}+\mathrm{CH}_{2} \mathrm{O}_{\mathrm{g}}+\mathrm{M}^{*}[8,10] \\
& \cdot \mathrm{CH}_{2} \mathrm{OH}_{\mathrm{g}}+\mathrm{CH}_{2} \mathrm{O}_{\mathrm{g}} \rightarrow \cdot \mathrm{CHO}_{\mathrm{g}}+\mathrm{CH}_{3} \mathrm{OH}_{\mathrm{g}}[8] \\
& \cdot \mathrm{CHO}_{\mathrm{g}}+\mathrm{M} \rightarrow \cdot \mathrm{H}_{\mathrm{g}}+\mathrm{CO}_{\mathrm{g}}+\mathrm{M}^{*}[8,10] \\
& \cdot \mathrm{CHO}_{\mathrm{g}}+\mathrm{CH}_{3} \mathrm{OH}_{\mathrm{g}} \rightarrow \mathrm{CH}_{2} \mathrm{O}_{\mathrm{g}}+\cdot \mathrm{CH}_{2} \mathrm{OH}_{\mathrm{g}} \\
& \cdot \mathrm{CHO}_{\mathrm{g}}+\mathrm{CH}_{2} \mathrm{O}_{\mathrm{g}} \rightarrow \mathrm{CO}_{\mathrm{g}}+\cdot \mathrm{CH}_{2} \mathrm{OH}_{\mathrm{g}} \\
& \cdot \mathrm{H}_{\mathrm{g}}+\mathrm{CH}_{3} \mathrm{OH}_{\mathrm{g}} \rightarrow \cdot \mathrm{CH}_{2} \mathrm{OH}_{\mathrm{g}}+\mathrm{H}_{2 \mathrm{~g}}[10] \\
& \cdot \mathrm{H}_{\mathrm{g}}+\mathrm{CH}_{3} \mathrm{OH}_{\mathrm{g}} \rightarrow \mathrm{H}_{2} \mathrm{O}_{\mathrm{g}}+\cdot \mathrm{CH}_{3 \mathrm{~g}}[10] \\
& \cdot \mathrm{H}_{\mathrm{g}}+\mathrm{CH}_{2} \mathrm{O}_{\mathrm{g}} \rightarrow \cdot \mathrm{CHO}_{\mathrm{g}}+\mathrm{H}_{2 \mathrm{~g}}[8,10] \\
& \cdot \mathrm{H}_{\mathrm{g}}+\mathrm{CH}_{2} \mathrm{O}_{\mathrm{g}} \rightarrow \cdot \mathrm{CH}_{2} \mathrm{OH}_{\mathrm{g}} \\
& \cdot \mathrm{CH}_{3 \mathrm{~g}}+\mathrm{CH}_{3} \mathrm{OH}_{\mathrm{g}} \rightarrow \mathrm{CH}_{4 \mathrm{~g}}+\cdot \mathrm{CH}_{2} \mathrm{OH}_{\mathrm{g}}[10] \\
& \cdot \mathrm{CH}_{3 \mathrm{~g}}+\mathrm{CH}_{2} \mathrm{O}_{\mathrm{g}} \rightarrow \mathrm{CH}_{4 \mathrm{~g}}+\cdot \mathrm{CHO}_{\mathrm{g}}[10] \\
& \cdot \mathrm{OH}_{\mathrm{g}}+\mathrm{CH}_{2} \mathrm{O}_{\mathrm{g}} \rightarrow \mathrm{H}_{2} \mathrm{O}_{\mathrm{g}}+\cdot \mathrm{CHO}_{\mathrm{g}} \\
& \cdot \mathrm{OH}_{\mathrm{g}}+\mathrm{CH}_{3} \mathrm{OH}_{\mathrm{g}} \rightarrow \mathrm{H}_{2} \mathrm{O}_{\mathrm{g}}+\cdot \mathrm{CH}_{2} \mathrm{OH}_{\mathrm{g}}[10]
\end{aligned}
$$

Finally, reactions between radicals and between radicals and surfaces will lead to chain termination (not listed), forming stable products. 
In this model, gas-phase $\cdot \mathrm{H}$ radicals are not formed via surface reactions because hydrogen was shown to be strongly adsorbed on $\mathrm{Na}_{2} \mathrm{CO}_{3}$ by the TPD and the transient isotope experiments.

We propose that the gas-phase radical $\cdot \mathrm{CH}_{2} \mathrm{OH}$ is formed by $\mathrm{H}-\mathrm{CH}_{2} \mathrm{OH}$ bond breaking on the surface (reaction (2)). Formation of the free radical $\mathrm{CH}_{3} \mathrm{O} \cdot$ by $\mathrm{CH}_{3} \mathrm{O}-\mathrm{H}$ bond breaking is not suggested in the model because the bond $\mathrm{CH}_{3} \mathrm{O}-\mathrm{H}$ is stronger than $\mathrm{H}-\mathrm{CH}_{2} \mathrm{OH}$ and the heat of formation of the $\mathrm{CH}_{3} \mathrm{O} \cdot$ radical is higher than that of $\cdot \mathrm{CH}_{2} \mathrm{OH}$, as shown in Table 1 . Similarly, the cleavage of $\mathrm{CH}_{3}-\mathrm{OH}$ to form the gas-phase radical $\cdot \mathrm{CH}_{3}$ is not considered to be important because this bond is polar and the heat of formation of $\cdot \mathrm{CH}_{3}$ is high, although the $\mathrm{CH}_{3}-\mathrm{OH}$ bond is weak.

The supposition that reactions (2) and (3) are reversible is supported by the transient isotope experiment where trideuterated methanol was observed. Reactions (3) - (5) are suggested to account for the direct formation of carbon monoxide and formaldehyde on the surface, which is especially important for a fresh catalyst [7]. Nevertheless, these reactions are minor when compared to the gas-phase chain reactions.

We suppose that hydrogen recombination and desorption from the surface (reaction (7)) is the rate-determining step. This is supported by the observation that when the catalyst was purged of methanol, conversion was greatly increased but formaldehyde selectivity remained unchanged [7]. This indicates that strongly adsorbed hydrogen accumulates on the catalyst and eventually slows the $\mathrm{H}-\mathrm{CH}_{2} \mathrm{OH}$ bond cleavage by blocking sites. When hydrogen is allowed to desorb during the purge, sites are freed and the $\mathrm{H}-\mathrm{CH}_{2} \mathrm{OH}$ bond cleavage can occur at a faster rate, until the catalyst surface is again saturated with hydrogen. Thus, it may be possible to improve the catalytic activity by accelerating the desorption of surface hydrogen. In fact, we have seen that mixing the carbonate with active carbons or transition metals (such as iron) increases the activity several-fold without decreasing the selectivity [7].

Formaldehyde decomposes significantly without a catalyst while methanol thermal decomposition is not important. This means that reaction (8) in the model is much faster than reaction (9). In addition, formaldehyde decompo-

\section{TABLE 1}

Bond strengths and heats of formations of related radicals [11]

\begin{tabular}{lll}
\hline Bond & $\begin{array}{l}\text { Bond energy } \\
D_{298}^{0} \\
(\mathrm{~kJ} / \mathrm{mol})\end{array}$ & $\begin{array}{l}\text { Radical formation heat } \\
H_{\mathrm{f} 298}^{0}(\mathrm{~kJ} / \mathrm{mol})\end{array}$ \\
\hline $\mathrm{H}-\mathrm{CH}_{2} \mathrm{OH}$ & 393 & $-26\left(\cdot \mathrm{CH}_{2} \mathrm{OH}\right)$ \\
$\mathrm{H}-\mathrm{OCH}_{3}$ & 437 & $16\left(\cdot \mathrm{OCH}_{3}\right)$ \\
$\mathrm{HO}-\mathrm{CH}_{3}$ & 382 & $142\left(\cdot \mathrm{CH}_{3}\right)$ \\
\hline
\end{tabular}


sition on the surface is not included in the model because it is less important than homogeneous reactions above $750 \mathrm{~K}$, where methanol dehydrogenation is normally conducted.

Among the gas-phase radical reactions, reactions (15)-(17) are the most important as propagation steps, since $\mathrm{H} \cdot$ radical is more active than the other radicals concerned [10].

The proposed reaction mechanism is in agreement with observed product distributions. According to the model, the predominant products are $\mathrm{H}_{2}, \mathrm{CH}_{2} \mathrm{O}$, $\mathrm{CO}, \mathrm{CH}_{4}$ and $\mathrm{H}_{2} \mathrm{O}$. Carbon monoxide is mainly produced by gas-phase decomposition of formaldehyde. Methane is formed through reaction (16), which is in parallel with reaction (15) $\left(\mathrm{CH}_{2} \mathrm{O}\right.$ formation). Since thermal decomposition of methanol (reaction (9)) is insignificant, methane selectivity is determined by the rates of reactions (15) and (16). According to Aronowitz et al. [10], reaction (16) is 15-30 times slower than reaction (15), the latter producing formaldehyde and carbon monoxide in further chain reactions. This is also in agreement with the observation in Fig. 2 that methane selectivity is around 0.04 .

In practice, carbon monoxide formation by formaldehyde decomposition must be minimized. This is especially important at high conversions since formaldehyde thermal decomposition is believed to be second-order [7,8] and methanol has a strong inhibitory effect on it [7]. Fast cooling of the products is necessary. A further decrease in methane selectivity, which is very low with this catalyst, seems impossible.

\section{CONCLUSIONS}

Methanol dehydrogenation is initiated principally by the $\mathrm{H}-\mathrm{CH}_{2} \mathrm{OH}$ bond cleavage on the surface to produce adsorbed hydrogen and gas-phase free radical $\cdot \mathrm{CH}_{2} \mathrm{OH}$ which undergoes chain reactions to produce formaldehyde, carbon monoxide and methane. The reaction rate is determined by hydrogen recombination and desorption from the surface. Formaldehyde and methane are mainly produced in the gas-phase by catalyst-initiated chain reactions. Carbon monoxide is principally formed from formaldehyde decomposition in the gas phase.

\section{ACKNOWLEDGEMENTS}

Financial support by the Swiss Federal Science Foundation is gratefully acknowledged. 


\section{REFERENCES}

1 J. Catalàn Cancho, A.M. Estévez Sànchez, A. Fernandez Tena and M.C. Màrquez Moreno, Chem. Biochem. Eng. Quarterly, 3 (1-2) (1989) 51.

2 S.J. Green and R.E. Vener, Ind. Eng. Chem., 47 (1) (1955) 103.

3 A. Meyer, Ph.D. Dissertation, No. 759, Swiss Federal Institute of Technology, Lausanne (1988).

4 Y. Matrumura, K. Hashimoto and S. Yoshida, J. Catal., 100 (1986) 392.

5 G. Wiesgickl, H.P. Beck and G. Emig, Appl. Catal., 59 (1990) L1.

6 A. Meyer and A. Renken, in M.J. Phillips and M. Ternan (Editors), Proc. 9th. Intern. Cong. Catal., Calgary, The Chemical Institute of Canada, Ottawa, 1988, Vol. 4, p. 1898.

7 S. Su, Ph.D. Dissertation, No. 970, Swiss Federal Institute of Technology, Lausanne (1991).

8 C.J. Chen and D.J. McKenney, Can. J. Chem., 50 (1972) 992.

9 A.J. Tench, D. Giles and J.F.J. Kibblewhite, Trans. Faraday Soc., 67 (1971) 854.

10 D. Aronowitz, D.W. Naegeli and I Glassman, J. Phys. Chem., 18 (1977) 2555.

11 R.C. Weast and M.J. Astle (Editors), CRC Hand Book of Chemistry and Physics, CRC Press, Boca Raton, FL, 63rd edn., 1982. 